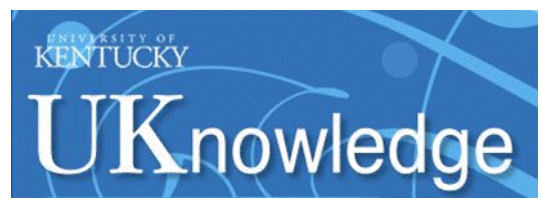

University of Kentucky

UKnowledge

\title{
9-25-2015
}

\section{Heterogeneous Oxidation of Catechol}

\author{
Elizabeth A. Pillar \\ University of Kentucky, epillar86@gmail.com \\ Ruixin Zhou \\ University of Kentucky, ruixin.zhou@uky.edu \\ Marcelo I. Guzman \\ University of Kentucky, marcelo.guzman@uky.edu
}

Follow this and additional works at: https://uknowledge.uky.edu/chemistry_facpub

Part of the Analytical Chemistry Commons, Biochemistry Commons, Environmental Chemistry Commons, Environmental Engineering Commons, Environmental Monitoring Commons, Laboratory and Basic Science Research Commons, Organic Chemistry Commons, Physical Chemistry Commons, Water Resource Management Commons, and the Wood Science and Pulp, Paper Technology Commons

Right click to open a feedback form in a new tab to let us know how this document benefits you.

\section{Repository Citation}

Pillar, Elizabeth A.; Zhou, Ruixin; and Guzman, Marcelo I., "Heterogeneous Oxidation of Catechol" (2015). Chemistry Faculty Publications. 26.

https://uknowledge.uky.edu/chemistry_facpub/26

This Article is brought to you for free and open access by the Chemistry at UKnowledge. It has been accepted for inclusion in Chemistry Faculty Publications by an authorized administrator of UKnowledge. For more information, please contact UKnowledge@lsv.uky.edu. 


\section{Heterogeneous Oxidation of Catechol}

Digital Object Identifier (DOI)

http://dx.doi.org/10.1021/acs.jpca.5b07914

\section{Notes/Citation Information}

Published in The Journal of Physical Chemistry A, v. 119, issue 41, p. 10349-10359.

Copyright @ 2015 American Chemical Society

ACS AuthorChoice - This is an open access article published under an ACS AuthorChoice License, which permits copying and redistribution of the article or any adaptations for non-commercial purposes. 


\title{
Heterogeneous Oxidation of Catechol
}

\author{
Elizabeth A. Pillar, Ruixin Zhou, and Marcelo I. Guzman* \\ Department of Chemistry, University of Kentucky, Lexington, Kentucky 40506, United States
}

\section{Supporting Information}

ABSTRACT: Natural and anthropogenic emissions of aromatic hydrocarbons from biomass burning, agro-industrial settings, and fossil fuel combustion contribute precursors to secondary aerosol formation (SOA). How these compounds are processed under humid tropospheric conditions is the focus of current attention to understand their environmental fate. This work shows how catechol thin films, a model for oxygenated aromatic hydrocarbons present in biomass burning and combustion aerosols, undergo heterogeneous oxidation at the air-solid interface under variable relative humidity $(\mathrm{RH}=0-90 \%)$. The maximum reactive uptake coefficient of $\mathrm{O}_{3}(\mathrm{~g})$ by catechol $\gamma_{\mathrm{O}_{3}}=(7.49 \pm 0.35) \times 10^{-6}$ occurs for $90 \% \mathrm{RH}$. Upon exposure of ca. $104-\mu \mathrm{m}$ thick catechol films to $\mathrm{O}_{3}(\mathrm{~g})$ mixing ratios between $230 \mathrm{ppbv}$ and $25 \mathrm{ppmv}$, three main reaction pathways are observed. (1) The cleavage of the 1,2 carbon-carbon bond at the air-solid interface resulting in the formation of cis,cis-muconic acid via primary ozonide and hydroperoxide intermediates. Further direct ozonolysis of cis,cis-muconic yields

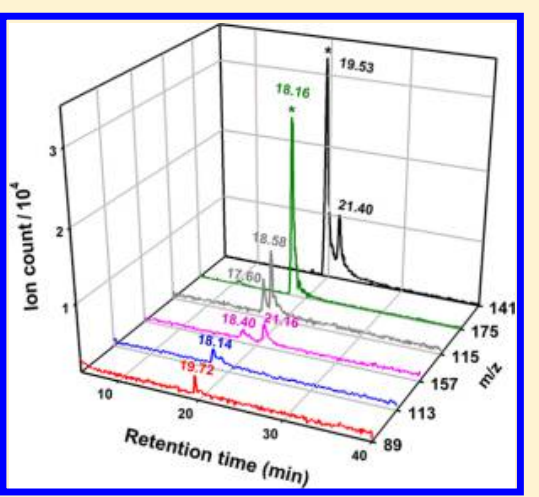
glyoxylic, oxalic, crotonic, and maleic acids. (2) A second pathway is evidenced by the presence of Baeyer-Villiger oxidation products including glutaconic 4-hydroxy-2-butenoic and 5-oxo-2-pentenoic acids during electrospray ionization mass spectrometry (MS) and ion chromatography MS analyses. (3) Finally, indirect oxidation by in situ produced hydroxyl radical $\left(\mathrm{HO}^{\bullet}\right)$ results in the generation of semiquinone radical intermediates toward the synthesis of polyhydoxylated aromatic rings such as tri-, tetra-, and penta-hydroxybenzene. Remarkably, heavier polyhydroxylated biphenyl and terphenyl products present in the extracted oxidized films result from coupling reactions of semiquinones of catechol and its polyhydroxylated rings. The direct ozonolysis of 1,2,3- and 1,2,4-trihydroxybenezene yields 2- and 3-hydroxy-cis,cis-muconic acid, respectively. The production of 2,4- or 3,4-dihdroxyhex-2-enedioic acid is proposed to result from the sequential processing of cis,cis-muconic acid, 2- and 3hydroxy-cis,cis-muconic acid. Overall, these reactions contribute precursors to form aqueous SOA from aromatics in atmospheric aerosols and brown clouds.

\section{INTRODUCTION}

Aerosol particles absorb and scatter sunlight and act as condensation nuclei for clouds, playing a key role in climate. ${ }^{1}$ The production mechanisms and associated properties of secondary organic aerosols (SOA) from laboratory and field studies have been recently reviewed. ${ }^{2,3}$ In situ aging of the species found in aerosols during atmospheric transport contributes to the chemical complexity that makes quantifying organic species in aerosols difficult. ${ }^{4}$ The concentration of water-soluble organic compounds (WSOCs) in field measurements, e.g., glyoxylic, 3-oxopropoanoic, oxalic, and fumaric acids, suggests common natural formation mechanisms. ${ }^{5}$ Because the high levels of WSOCs quantified at dissimilar geographical locations can exceed typical urban pollution sources, $^{6-8}$ the identification of new chemical production mechanisms acting over emissions from natural processes is needed.

The composition of WSOCs, atmospheric transport of biomass burning products, and photooxidation (e.g., of glyoxylic acid to generate oxalic acid) have been correlated at different sites. ${ }^{6-8}$ Dihydroxybenzenes such as catechol are the most common gas-phase organic constituents ( $\sim 50$ ppbv) resulting from biomass burning, ${ }^{9}$ pyrolysis, and combustion. ${ }^{10}$ Cloud water collected from brown clouds also contains aromatics such as catechol rings substituted with methyl, carbonyl, and nitro groups. ${ }^{11}$ The surfactant properties of these species favor their accommodation at interfaces of aerosols, ${ }^{12}$ where they are prone to undergo photooxidation. ${ }^{13}$

A recent study demanded the identification and quantification of products from catechol ozonolysis both in gas and particle phases. ${ }^{14}$ In fact, the heterogeneous ozonolysis of catechol under ultrafast contact times ${ }^{15,16}$ has been the subject of our previous study at the air-water interface of microdroplets. ${ }^{17}$ Mass spectrometry (MS) analysis of the reaction products has revealed that different reaction channels are operative at the air-water interface: (1) oxidative cleavage of the aromatic ring and (2) hydroxylation. ${ }^{17,18}$ The cleavage of $\mathrm{C}(\mathrm{OH})-\mathrm{C}(\mathrm{OH})$ bond of catechol yields cis,cis-muconic acid (MA $)^{19,20}$ and its lower molecular weight (LMW) carboxylic acid oxidation products. ${ }^{17,21}$ Attenuated total reflectance (ATR) Fourier transform infrared (FTIR) spectroscopy has been used to study the reaction of solid films under high relative humidity $(\mathrm{RH})$ that yielded an uptake coefficient of

Received: August 14, 2015

Revised: September 21, 2015

Published: September 25, 2015 
ozone by catechol $\gamma_{\mathrm{O}_{3}}=5.6 \times 10^{-5}(\mathrm{RH}=81 \%)^{20}$ that is about 20-times larger than the value estimated at the air-water interface $\left(\gamma_{\mathrm{O}_{3}}=2.73 \times 10^{-6}\right) .{ }^{17}$ Indeed, an explanation to this discrepancy justifies a new independent study to explore the values of $\gamma_{\mathrm{O}_{3}}$ at variable $\mathrm{RH}$. The hydroxylation channel leading to the production of semiquinone radicals explains the in situ interfacial formation of polyhydroxylated aromatic rings and chromophoric quinones in tropospheric particles. ${ }^{17}$ However, the production of semiquinone radicals should also result in the formation of coupling aromatic products such as biphenyls during ozonolysis. Therefore, this work is focused on the identification of coupling products from catechol and in situ produced polyhydroxylated benzene rings during the heterogeneous ozonolysis of thin catechol films. The results reported herein provide new insights into the evolution of biomass burning and combustion emissions during atmospheric transport.

\section{EXPERIMENTAL SECTION}

Thin-Film Preparation. Solutions of ca. $3.0 \mathrm{mg} \mathrm{mL}^{-1}$ catechol (Sigma-Aldrich, 99.9\%) were prepared daily in isopropanol (Fisher Optima, 99.9\%). A glass syringe with stainless steel plunger and needle (Hamilton, 705) was used for dropwise addition of $50 \mu \mathrm{L}$ of solution onto an infrared transparent optical window. Polished $\mathrm{ZnSe}$ or amorphous material transmitting infrared radiation (AMTIR) $2.0 \mathrm{~mm}$ thick optical windows with a diameter of $13.0 \mathrm{~mm}$ (PIKE) were used. After $3 \mathrm{~h}$ of solvent evaporation, dry films were confirmed to be stable by FTIR spectroscopy. The resulting film thickness measured by reflectance spectroscopy was ca. $104.5( \pm 12.8)$ $\mu \mathrm{m}$, and the film contained ca. $150 \mu \mathrm{g}$ of catechol deposited. Thin films of some candidate products were similarly prepared using cis,cis-muconic acid (Aldrich, 98.7\%), maleic acid (SigmaAldrich, 99.9\%), glyoxylic acid (Aldrich, 51.7 wt \% in water), oxalic acid (Sigma-Aldrich, 99.9\%), 1,2,3-trihydroxybenzene (Acros, 99.7\%), and 1,2,4-trihydroxybenzene (Alfa Aesar, 99.2\%).

Ozonolysis of Thin Films. A customized ozone generation and monitoring system was used in all experiments. ${ }^{16,17}$ Humid nitrogen was produced by passing $\mathrm{N}_{2}(\mathrm{~g})$ (Scott Gross, UHP) through a wash bottle containing ultrapure water $(18.2 \mathrm{M} \Omega \mathrm{cm}$, ELGA PURELAB flex, Veolia). The mixing ratio of dry $\mathrm{O}_{3}(\mathrm{~g})$ and humid $\mathrm{N}_{2}(\mathrm{~g})$ was controlled with flow meters (Aalborg). The relative humidity of the mixed gas $\left(1.0 \mathrm{~L} \mathrm{~min}^{-1}\right)$ was monitored in a mixing chamber with a remote hygrometer (Traceable) before flowing into a borosilicate glass flowthrough reactor $(3.785 \mathrm{~L}$ capacity) provided with a Tefloncoated lid (Scheme 1). The gas was allowed to equilibrate for 1

Scheme 1. Flow-Through Reactor System with Mixing of Dry and Wet Gases

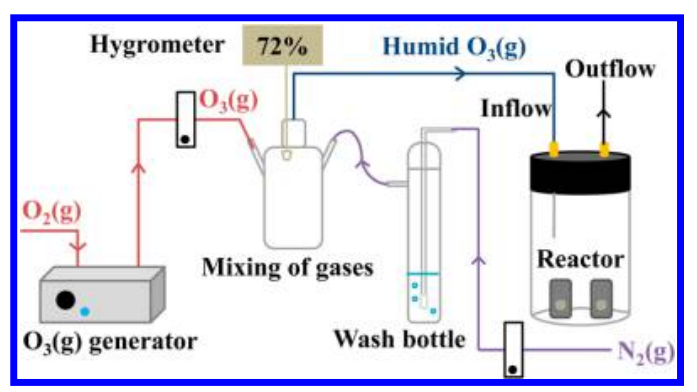

$\mathrm{h}$ before any samples were introduced into the reactor. Ultraviolet (UV)-visible absorption measurements at wavelengths $\lambda_{1}=250 \mathrm{~nm}$ and $\lambda_{2}=300 \mathrm{~nm}$ were performed for a 1.0 $\mathrm{L} \mathrm{min}^{-1}$ gas flow entering the chamber in a $10.00 \mathrm{~cm}$ path length fused silica cuvette (Starna Cell) before, during, and after the reaction and converted to $\left[\mathrm{O}_{3}(\mathrm{~g})\right]$ using absorption cross sections $\sigma_{250 \mathrm{~nm}}=1.1 \times 10^{-17} \mathrm{~cm}^{2}$ molecule ${ }^{-1}$ and $\sigma_{300 \mathrm{~nm}}$ $=3.9 \times 10^{-19} \mathrm{~cm}^{2}$ molecule ${ }^{-1}$, respectively. ${ }^{22}$ The standard deviation associated with measured $\left[\mathrm{O}_{3}(\mathrm{~g})\right]$ during the reactions was below $2.50 \%$.

FTIR and UV-Visible Monitoring. The spectroscopic changes associated with the oxidation of thin films were studied by FTIR spectroscopy. Optical windows with prepared films were mounted on stainless steel plates, placed in the reactor, and withdrawn for FTIR analysis at $20 \mathrm{~min}$ intervals of exposure to $\mathrm{O}_{3}(\mathrm{~g})$, unless indicated otherwise. FTIR analysis was performed with a Nicolet iN10 infrared microscope (Thermo Scientific). An average of 64 scans were collected in $1.5 \mathrm{~min}$ over the range $500-4000 \mathrm{~cm}^{-1}$ with $4 \mathrm{~cm}^{-1}$ resolution using an iZ10 FT-IR module connected to the infrared microscope. All samples were background subtracted using an empty optical window. Control experiments ensured that films exposed to humid air in the absence of $\mathrm{O}_{3}(\mathrm{~g})$ were chemically stable and that their loss by sublimation remained below $5.0 \%$ during the time scale of experiments designed to gather kinetic information. Reported data are the average of duplicate experiments with error bars corresponding to one standard deviation. OMNIC software (Thermo Scientific) was utilized for FTIR spectroscopy and for data processing. The CD line, or corrected peak heights after baseline correction as previously described, ${ }^{17}$ is reported in all plots. Data analysis and fitting of rate constants was performed using SigmaPlot Software (Systat). UV-visible absorption measurements of films deposited on quartz optical windows followed the same procedure described above.

Film Extraction and Analysis. Each window with a film was extracted with $2.0 \mathrm{~mL}$ of selected solvents under sonication (Branson Ultrasonics) for $15 \mathrm{~min}$. Extractions were performed using four different solvents: chloroform (Mallinckrodt, 99.8\%), isopropanol, acetone (Fisher Scientific, 99.5\%), or acetonitrile (Fisher Optima, 99.9\%). After sonication, the samples were quantitatively transferred to $7.5 \mathrm{~mL}$ amber vials (Fisher Scientific) and dried by gently sparging $\mathrm{N}_{2}(\mathrm{~g})$. All samples were finally reconstituted with $1.0 \mathrm{~mL}$ of methanol (Fisher Optima, 99.99\%) unless stated otherwise. Control experiments showed that unreacted dry and humid catechol films extracts remain stable during the time scale of the reaction.

The analysis of reconstituted film extracts was performed by electrospray ionization (ESI) MS in a MSQ Plus instrument (Thermo Scientific) operating in negative ion mode. Samples were injected into the calibrated ESI MS instrument at a flow rate of $100 \mu \mathrm{L} \mathrm{min}{ }^{-1}$ by mixing equal flows of the reconstituted sample in methanol and ultrapure water $(18.2 \mathrm{M} \Omega \mathrm{cm}$, Elga Purelab flex, Veolia). The ESI MS conditions were as follows: drying gas temperature, $250{ }^{\circ} \mathrm{C}$; nebulizer voltage, $-1.9 \mathrm{kV}$; cone voltage, $-50 \mathrm{~V}$; and nebulizer pressure, $70 \mathrm{psi}$. Reported ion counts were background subtracted from the solvent and acquired over fixed intervals ( $\geq 30 \mathrm{~s})$.

Confirmation of the generation of carboxylic acids was obtained by ion chromatography (IC) MS analysis as described previously. ${ }^{23}$ For these analyses, dried film extracts were reconstituted in $1.5 \mathrm{~mL}$ of water and injected with a Dionex AS autosampler into a Dionex ICS-2000 IC system. The IC was 
equipped with an IonPac AS11-HC column $(2 \times 250 \mathrm{~mm})$, an AG11-HC guard column $(2 \times 50 \mathrm{~mm})$, an ASRS-300 suppression module $(2 \mathrm{~mm})$, an eluent generator (EGC III) with $\mathrm{KOH}$ cartridge, and a CR-ATC anion trap column. The separation gradient applied a flow of $0.38 \mathrm{~mL} \mathrm{~min}^{-1}$ with an initial mobile phase of $1 \mathrm{mM} \mathrm{KOH}$ for $8 \mathrm{~min}$ followed by three linear increases of (1) $1.4 \mathrm{mM} \mathrm{min}^{-1}$ up to $15 \mathrm{mM}$, (2) 1.5 $\mathrm{mM} \mathrm{min}^{-1}$ up to $30 \mathrm{mM}$, and (3) $3 \mathrm{mM} \mathrm{min}^{-1}$ up to $60 \mathrm{mM}$. After IC separation, the eluent was mixed with $0.12 \mathrm{~mL} \mathrm{~min}^{-1}$ methanol for identification of the mass-to-charge ratio $(\mathrm{m} / \mathrm{z})$ of separated components in the ESI MS (drying gas temperature, $450{ }^{\circ} \mathrm{C}$; nebulizer voltage, $-1.9 \mathrm{kV}$; cone voltage, $-50 \mathrm{~V}$; and nebulizer pressure, $70 \mathrm{psi}$ ). Chromeleon and Excalibur software were used to control and process data.

\section{RESULTS AND DISCUSSION}

Oxidation of Catechol Films. Figure 1 shows FTIR spectra of catechol thin films (A) under ambient conditions and

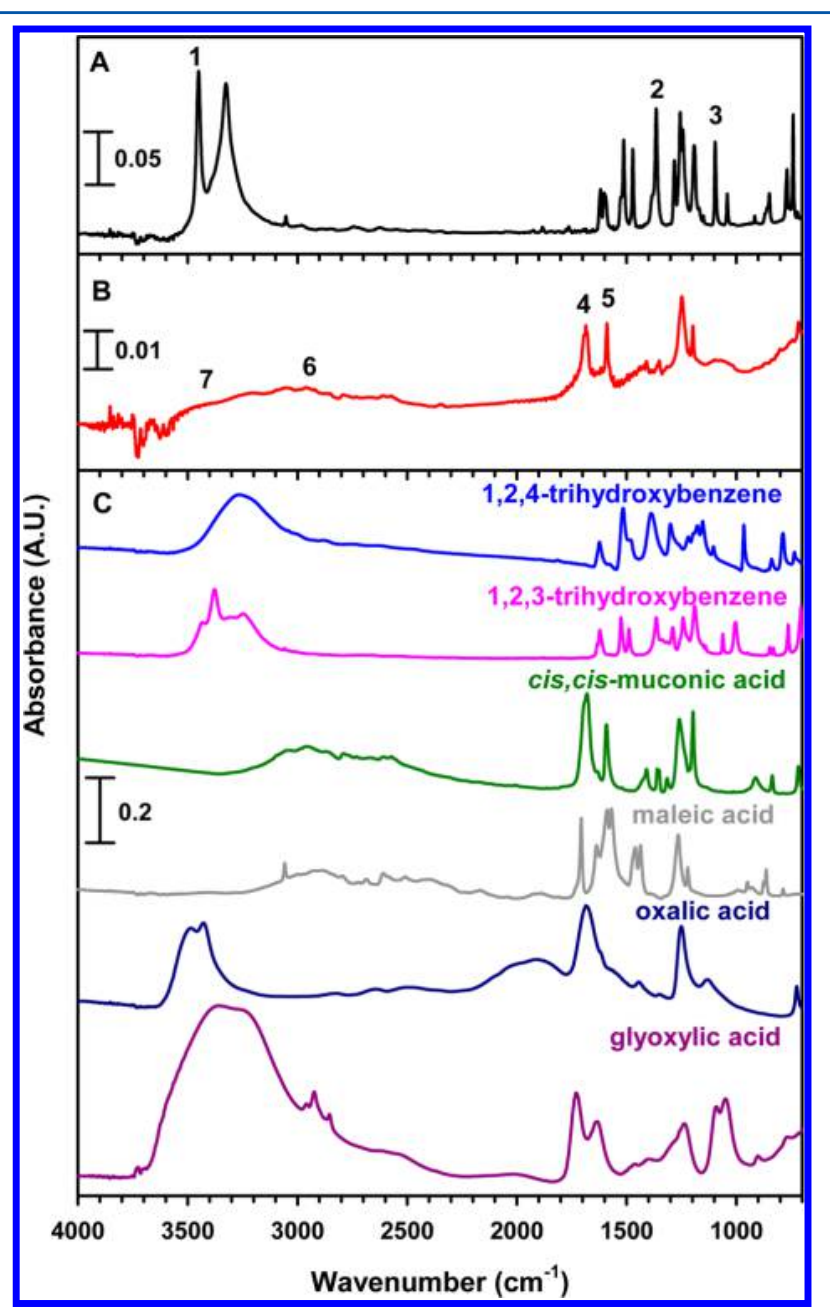

Figure 1. FTIR spectra of thin films of catechol (A) before and (B) after $24 \mathrm{~h}$ of exposure to $230 \mathrm{ppbv} \mathrm{O}_{3}(\mathrm{~g})$ at $68 \%$ relative humidity $(\mathrm{RH})$; (C) spectra for standards with features observed in oxidized films.

(B) after exposure to $230 \mathrm{ppbv} \mathrm{O}_{3}(\mathrm{~g})$ at $68 \% \mathrm{RH}$ for $24 \mathrm{~h}$. All infrared spectroscopic features for pure catechol in Figure $1 \mathrm{~A}$ are assigned to vibrational modes in Table S1 (Supporting Information). After exposure to $\mathrm{O}_{3}(\mathrm{~g})$, the features in Figure $1 \mathrm{~A}$ for $\mathrm{O}-\mathrm{H}$ stretching, $\mathrm{C}-\mathrm{C}$ stretching, and $\mathrm{C}-\mathrm{H}$ bending peaks of catechol at $3450 \mathrm{~cm}^{-1}$ (peak 1), $1365 \mathrm{~cm}^{-1}$ (peak 2), and $1095 \mathrm{~cm}^{-1}$ (peak 3), respectively, are lost in Figure 1B.

Instead, new signals for $\mathrm{C}=\mathrm{O}$ stretching at $1680 \mathrm{~cm}^{-1}$ (peak 4), $\mathrm{C}=\mathrm{C}$ asymmetric stretching at $1585 \mathrm{~cm}^{-1}$ (peak 5), $\mathrm{O}-\mathrm{H}$ stretching for carboxylic acid at $2400-3100 \mathrm{~cm}^{-1}$ (peak 6), and hydrogen-bonded $\mathrm{O}-\mathrm{H}$ stretching at $\sim 3400 \mathrm{~cm}^{-1}$ (peak 7) become prominent in the ozonolysis products spectrum (Figure 1B).

Figure 1C displays the IR spectra, from top to bottom, of (blue trace) 1,2,4-trihydroxybenzene, (pink trace) 1,2,3trihydroxybenzene, (green trace) cis,cis-muconic acid, (gray trace) maleic acid, (dark blue trace) oxalic acid, and (purple trace) glyoxylic acid, which represent candidate products from our ozonolysis study at the air-water interface. ${ }^{17}$ The main features observed in Figure 1B, peaks 4-6, partially resemble those of cis,cis-muconic acid. ${ }^{20}$ However, there is an additional level of complexity associated with peaks 4, 5 and 7, which cannot be explained by cis,cis-muconic acid alone. For example, maleic acid and both trihydroxybenzene species have features that might contribute significantly to peak 5 , which is not observed in cis,cis-muconic acid, ${ }^{20}$ being as intense as peak 4 . These species, combined with glyoxylic and oxalic acids, may also explain the appearance of additional hydrogen-bonded $\mathrm{O}-$ $\mathrm{H}$ stretching modes giving rise to the broad peak centered at about $3400 \mathrm{~cm}^{-1}$. Tables with the vibrational assignments for the oxidized film, cis,cis-muconic acid, maleic acid, glyoxylic acid, oxalic acid, and 1,2,3- and 1,2,4-trihydroxybenzene are available in the Supporting Information (Tables S2-S8).

Detailed qualitative information on the products of catechol oxidation at the air-solid interface is gleaned from long-lasting experiments ( $24 \mathrm{~h}$ exposure) at ozone levels approaching those typical of highly polluted urban environments (Figure 1). ${ }^{24}$ However, this experiment is slow and yields kinetics results that may be biased because of the loss of catechol by sublimation occurring at long time scales. For example, a control experiment with pure $\mathrm{N}_{2}(\mathrm{~g})$ flow at $68 \% \mathrm{RH}$ shows a catechol loss by sublimation of $80 \%$ after $24 \mathrm{~h}$. Therefore, the experiments below are designed to constrain the sublimation loss of catechol during the reaction to be $\leq 5.0 \%$ by increasing $\left[\mathrm{O}_{3}(\mathrm{~g})\right]$ to shorten their duration and provide valuable reaction rate constants.

Figure 2 shows the FTIR spectra of thin films with $150 \mu \mathrm{g}$ of catechol deposited, which are exposed to $23.6 \mathrm{ppmv} \mathrm{O}_{3}(\mathrm{~g})$ at $72 \% \mathrm{RH}$ for $3 \mathrm{~h}$. Ongoing work in our laboratory suggests a Langmuir-Hinshelwood mechanism is followed during the ozonolysis of catechol films. ${ }^{25}$ The data in Figures 1 and 2 are in linear region of the hyperbola describing the dependence of the rate of reaction on $\left[\mathrm{O}_{3}(\mathrm{~g})\right]$. Monitoring the loss of peaks 1-3 and the appearance of peaks 4-6 allows us to register the corresponding oxidation of catechol and the development of organic acids and polyhydroxylated aromatics products, respectively. The product distribution similar to that obtained for $230 \mathrm{ppbv}_{3}(\mathrm{~g})$ (Figure 1) confirms that the information gathered for larger $\left[\mathrm{O}_{3}(\mathrm{~g})\right]$ does not affect the oxidation mechanism at the air-solid interface. Clearly, features of the primary product cis,cis-muconic acid are evident in Figure 2, as well as $\mathrm{O}-\mathrm{H}\left(1410 \mathrm{~cm}^{-1}\right)$ and $=\mathrm{C}-\mathrm{H}$ bending modes $(1360$ and $\left.1320 \mathrm{~cm}^{-1}\right)$. Moreover, a defined peak centered at 3400 $\mathrm{cm}^{-1}$ is visible together with distinct broadening stretches for $\mathrm{C}=\mathrm{O}$ and $\mathrm{C}=\mathrm{C}$ at 1680 and $1590 \mathrm{~cm}^{-1}$, respectively. ${ }^{26}$

The sharp peak clearly appearing at $1198 \mathrm{~cm}^{-1}$ in the FTIR spectra of Figures 1 and 2 for final oxidation times also corresponds to cis,cis-muconic acid vibrational modes. This 


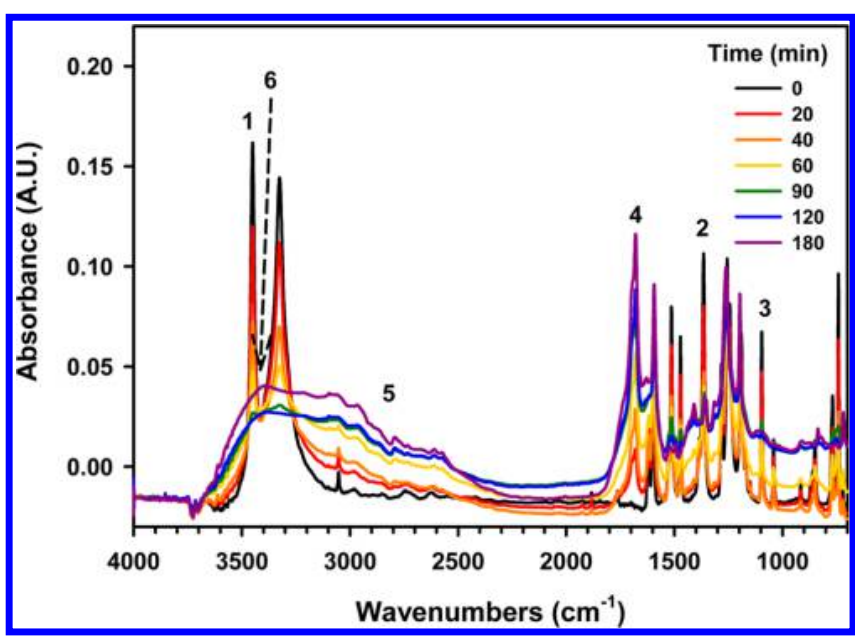

Figure 2. FTIR spectra showing the time series of catechol thin films exposed to 23.6 ppmv $\mathrm{O}_{3}(\mathrm{~g})$ at $72 \% \mathrm{RH}$. Peak labels $1-6$ indicate characteristic peaks used to monitor reaction progress (see text).

peak is $8 \mathrm{~cm}^{-1}$ above the closest peak for catechol and cannot be confused with a reactant signal. In general, the common spectroscopic features of several candidate products in the infrared region prevent the assignment of all products conclusively based on FTIR results. The critical need to resolve further the chemical composition of oxidized catechol led us to extract the films and analyze them by different techniques as described below.

Proposed Reaction Pathways Based on the Analysis of Extracted Films. Figure 3 shows ESI MS analyses of catechol films at $71 \% \mathrm{RH}$ (blue) before and (red) after $3 \mathrm{~h}$ of exposure to $29.3 \mathrm{ppmv} \mathrm{O}_{3}(\mathrm{~g})$, which were extracted in (1) acetonitrile, (2) acetone, (3) isopropanol, and (4) chloroform. The selection of these solvents with different properties ensures that peak identification of products is not affected by any artifacts resulting from the extraction procedure itself. In addition, the possibility of methanol clustering of parent anions during infusion of all samples in 50:50 methanol:water solvent is discarded because the corresponding adducts would have an excess mass of $+32 \mathrm{Da}$, which are absent in the MS spectra of Figure 3.

In the absence of ozone (blue trace in Figure 3), only catechol $(m / z 109)$ is detected as its monovalent ion corresponding to a general formula $\mathrm{C}_{6} \mathrm{H}_{4}(\mathrm{OH}) \mathrm{O}^{-}$. Numerous new product peaks are registered during the analysis of the oxidized film. Some of these products are the same as those observed during the ozonolysis of catechol at the air-water interface: glyoxylic acid (detected as glyoxylate ion with $\mathrm{m} / \mathrm{z}$ $73)$, crotonic acid $(m / z 85)$ or an isomer (e.g., 4-hydroxycrotonaldehyde), oxalic acid $(\mathrm{m} / z$ 89), maleinaldehydic acid $(\mathrm{m} / z$ 99), 4-hydroxy-2-butenoic acid $(\mathrm{m} / z$ 101), 5-oxo-3pentenoic acid $(m / z 113)$, maleic acid $(m / z 115)$, glutaconic acid $(m / z 129)$, and cis,cis-muconic acid $(m / z 141)$. Because the origin of these species has been explained in detail in our previous work, ${ }^{17}$ the discussion below first summarizes those reactions (see Scheme 2) and then is focused on elucidating the pathways for the production of new molecules observed as anions at $m / z 157,175,217,249,297,311$, and $325 \mathrm{amu}$ (Figure 3).

A direct electrophilic attack of $\mathrm{O}_{3}(\mathrm{~g})$ to catechol ${ }^{27}$ breaks the aromaticity between carbons 1 and 2 . The sequential process starts with the formation of a primary ozonide precursor to a

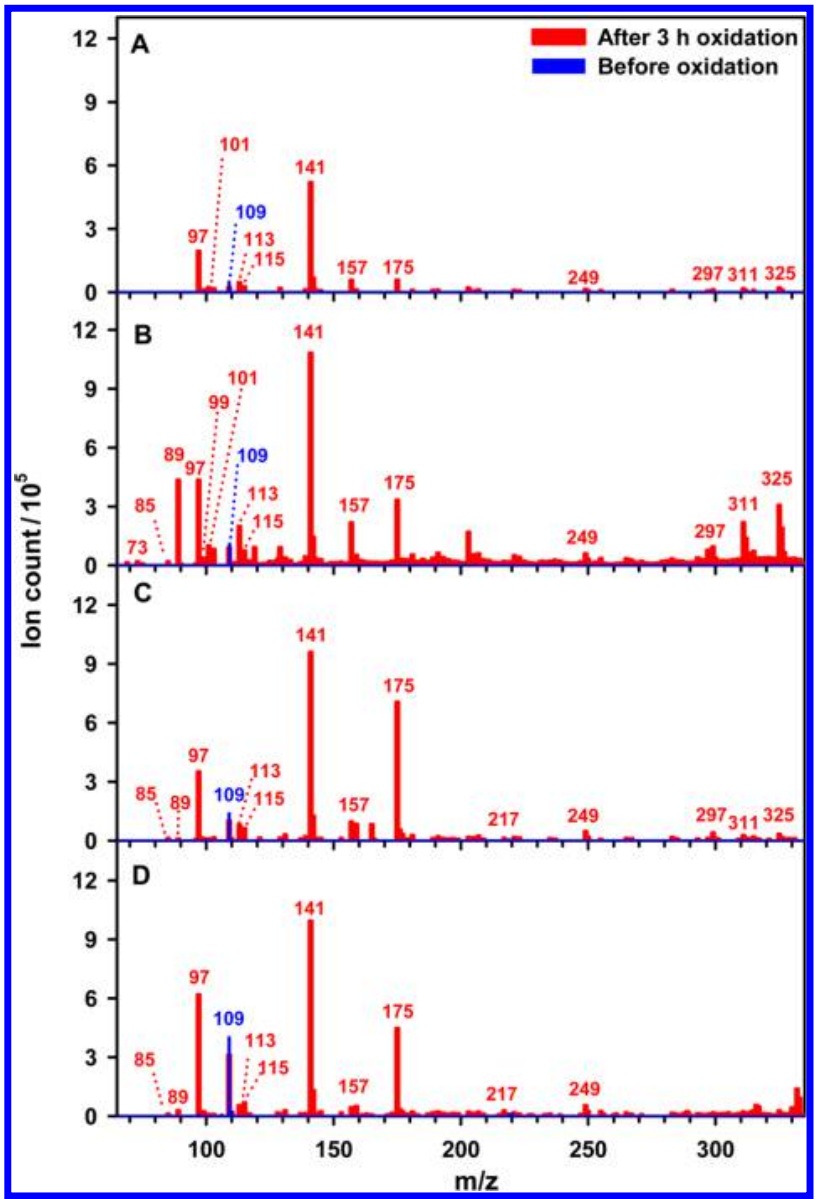

Figure 3. ESI MS spectra of catechol thin films (blue trace) before and (red trace) after $3 \mathrm{~h}$ of exposure to $29.3 \mathrm{ppmv} \mathrm{O}_{3}(\mathrm{~g})$ at $71 \% \mathrm{RH}$ extracted in (A) chloroform, (B) isopropanol, (C) acetone, and (D) acetonitrile.

Criegee intermediate, which yields a hydroperoxide that is converted in cis,cis-muconic acid $(m / z 141)$ and $\mathrm{H}_{2} \mathrm{O}_{2} \cdot{ }^{28}$ The primary direct ozonolysis product in Scheme 2, cis,cis-muconic acid, is oxidized ${ }^{29}$ to form maleinaldehydic acid $(\mathrm{m} / z$ 99), glyoxylic acid $(m / z 73)$, maleic acid $(m / z 115)$, and oxalic acid $(m / z 89)$. Scheme 2 also summarizes the formation of 4 hydroxy-2-butenoic acid $(m / z 101)$, 5-oxo-3-penteneoic acid $(m / z 113)$, and glutaconic acid $(m / z 129)$, resulting from Baeyer-Villiger (BV) oxidation of cis,cis-muconic acid. ${ }^{17,30}$

However, the appearance of new products with $\mathrm{m} / z 157$ and 175 in Figure 3 has escaped detection in experiment at the airwater interface ${ }^{17}$ and requires new pathways describing their production. Thermodynamically favorable electron transfer between 1,2-dihydroxy-aromatics such as catechol and dissolved $\mathrm{O}_{3}$ yields $o$-semiquinone and ozonide $\left(\mathrm{O}_{3}{ }^{\bullet-}\right)$ radicals directly. ${ }^{31}$ In the presence of water, the ozonide radical $\mathrm{O}_{3}{ }^{\bullet-}$ is quickly converted into $\mathrm{HO}^{\bullet},{ }^{17}$ which contributes to the degradation of catechol with a rate constant $k_{\mathrm{HO}}{ }^{\circ}$-catechol $=1.1$ $\times 10^{10} \mathrm{M}^{-1} \mathrm{~s}^{-1}$. ${ }^{32}$ Similarly, produced polyhydroxylated species undergo reactions with $\mathrm{HO}^{\circ}$. In addition to electron transfer, the production of $o$-semiquinone radicals is also possible after $\mathrm{HO}^{\bullet}$ attacks catechol forming trihydroxycyclohexadienyl radicals that undergo dehydration. ${ }^{17}$

Two channels for the production of the primary products from hydroxylation, 1,2,3- and 1,2,4-trihydroxybenzene, are possible. ${ }^{17}$ The first channel results from the reaction of $\mathrm{O}_{2}$ 
Scheme 2. Products from Catechol Oxidation by $\mathrm{O}_{3}(\mathrm{~g})$ and $\mathrm{HO}^{\bullet}$ Radical from Ref $17^{a}$

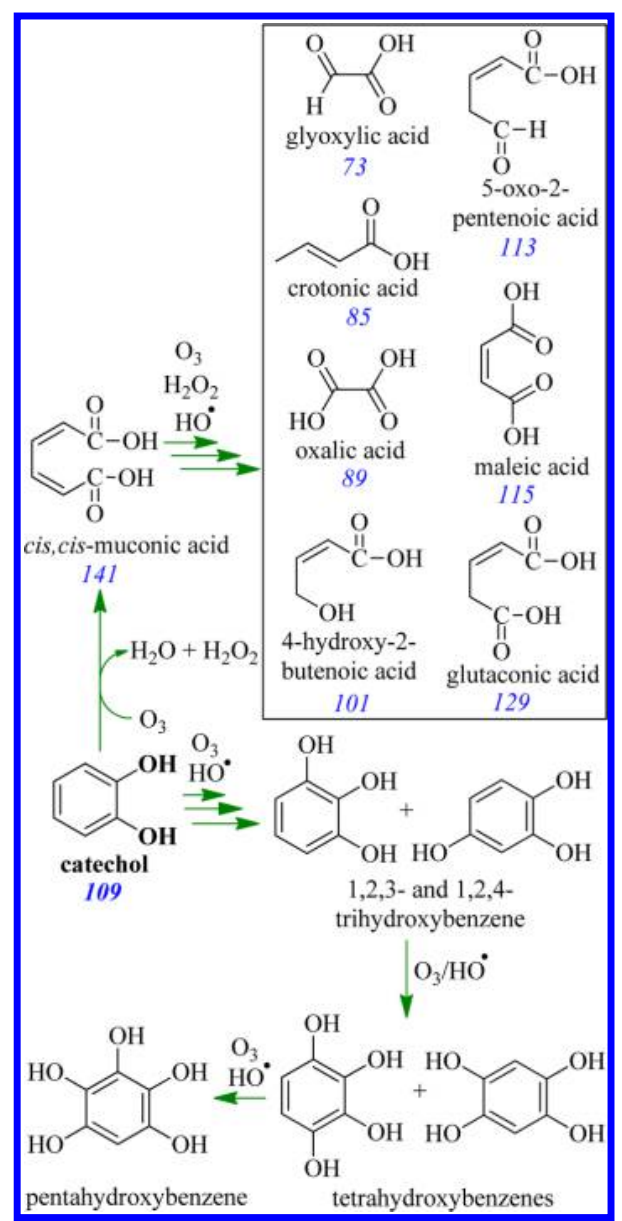

${ }^{a}$ The $m / z$ values of species observed during ozonolysis at the air-solid interface are given in blue font.

with 1,2,3- or 1,2,4-trihydroxycyclohexadienyl radical intermediates that also release hydroperoxyl radicals $\left(\mathrm{HO}_{2}{ }^{\bullet}\right) .{ }^{17}$ The second reaction channel at the air-solid interface is the direct attack of $\mathrm{O}_{3}$ to $\mathrm{C}_{3}$ or $\mathrm{C}_{6}$ of catechol that release $\mathrm{O}_{2}\left({ }^{1} \Delta_{\mathrm{g}}\right)$ en route to produce 1,2,3- and 1,2,4-trihydroxybenzene. ${ }^{3,34}$ Once produced, trihydroxybenzenes can undergo reactions similar to those described above to sequentially form tetrahydroxybenzene and pentahydroxybenzene products (Scheme 2). ${ }^{17}$

The confirmation that several dicarboxylic acids are reaction products is obtained by IC MS analysis showing in Figure 4 the extracted ion chromatograms for the most abundant species with $m / z 89,113,115,141,157$, and 175 . These species remained undetected during control experiments without ozone. The previously proposed mechanism of direct ozonolysis of catechol at the air-water interface is useful to guide the assignment of previously identified anionic products in Figures 3 and 4 as displayed in Scheme 2 and summarized above. $^{17}$

Among the new molecules in Figures 3 and 4 are 2hydroxyhexa-2,4-dienedioic acid and/or 3-hydroxyhexa-2,4dienedioic acid (both $\mathrm{m} / z$ 157) and 2,4- or 3,4-dihydroxyhex2-enedioic acid $(\mathrm{m} / z$ 175). These species can be explained based on the indirect oxidation of catechol and its primary oxidation products. Direct ozonolysis of previously produced trihydroxybenzene precursors forms aliphatic species with

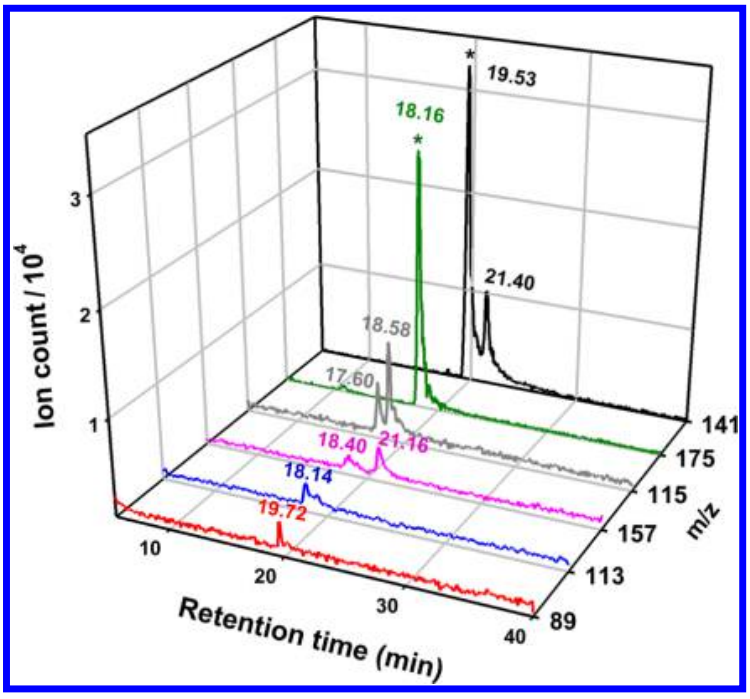

Figure 4. Extracted ion chromatograms during IC MS analysis of catechol film exposed to 29.3 ppmv $\mathrm{O}_{3}(\mathrm{~g})$ at $71 \% \mathrm{RH}$ for $3 \mathrm{~h}$. Peaks marked with an asterisk are scaled down by a factor of 2 .

neutral mass $158 \mathrm{Da}$ such as 2-hydroxyhexa-2,4-dienedioic acid and 3-hydroxyhexa-2,4-dienedioic acid (Scheme 3). The

Scheme 3. Proposed Reactions Producing Species with $\mathrm{m} / z$ 157 and 175

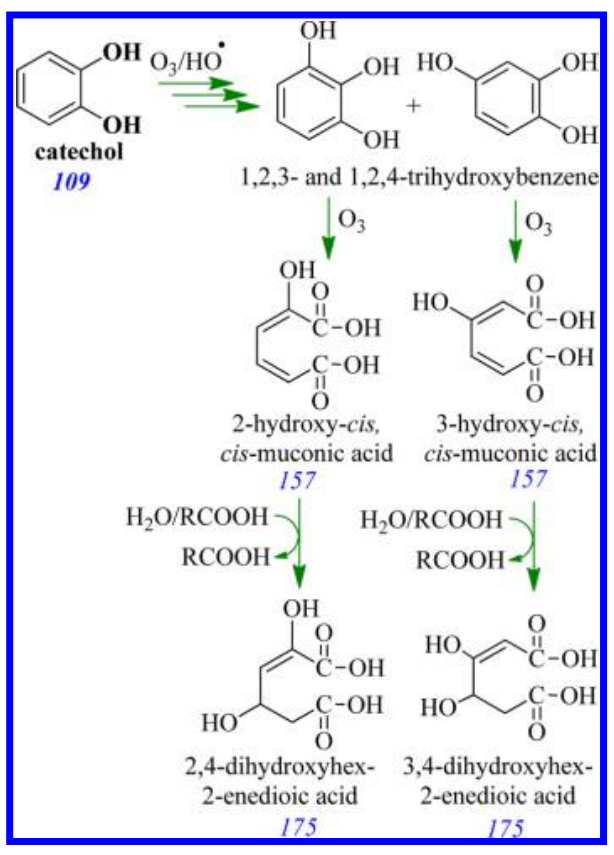

hydration of a double bond from 2- or 3- hydroxy-muconic acids occurs in the presence of oxidants, freshly formed carboxylic acids, and water on the reactive surface. The mechanism of hydration of 2- and 3-hidroxy-cis,cis-muconic acid in Scheme 3 is acid catalyzed by the carboxylic acids formed during direct ozonolysis (Scheme 2), which facilitates the production of the species with $m / z 175$, such as 2,4- or 3,4dihdroxyhex-2-enedioic acid. Alternatively, the two-step addition of $\mathrm{HO}^{\bullet}$ to cis,cis-muconic acid (not included in Scheme 2) may result in the production of species with mass $176 \mathrm{Da}$. The proposed mechanism of indirect oxidation by in situ produced $\mathrm{HO}^{\bullet}$ at the air-water interface ${ }^{17}$ rationalizes the 
Scheme 4. Proposed Reactions Producing Tetrahydroxy-biphenyls and Hexahydroxy-terphenyls

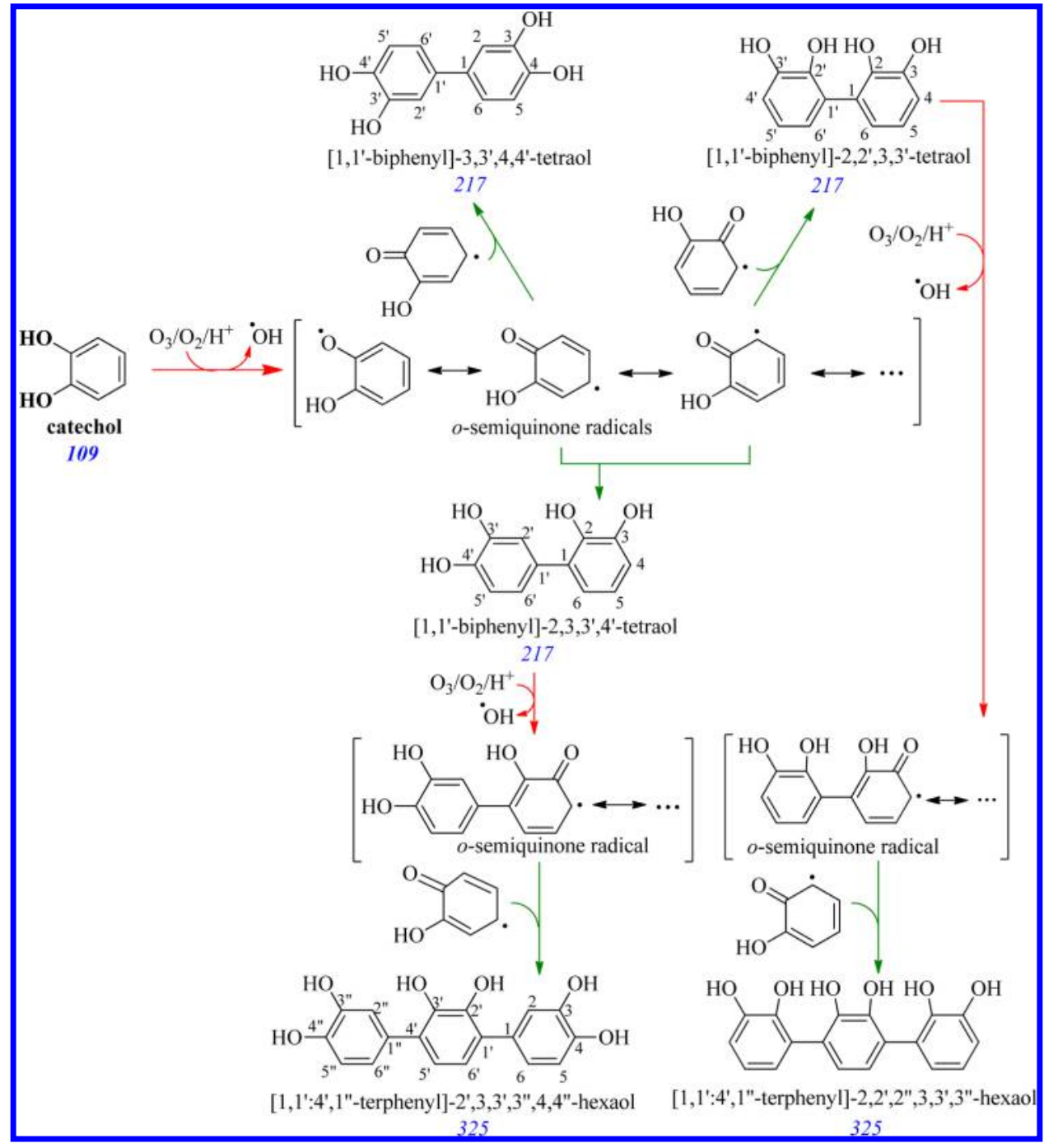

generation of $o$-semiquinone radicals precursor needed in several reactions leading to the species in Figure 3. Radical coupling of semiquinone functionalities is involved in the production of condensed polyphenol rings. The $o$-semiquinone radicals have been shown to exist at the air-water interface ${ }^{17}$ and should be able to undergo coupling reactions.

Dihydroxy-biphenyl isomeric species with $m / z 217$ in Figure 3 formed by coupling reactions can by represented by molecules such as $\left[1,1^{\prime}\right.$-biphenyl $]-2,2^{\prime}, 3,3^{\prime}$-tetraol, [1,1'biphenyl $]-3,3^{\prime}, 4,4^{\prime}$-tetraol, and $\left[1,1^{\prime}\right.$-biphenyl $]-2,3,3^{\prime}, 4^{\prime}$-tetraol (Scheme 4). The low intensity of this peak with $\mathrm{m} / z 217$ indicates that reactive biphenyls are quickly consumed in the production of heavier coupling products. The related generation of cross-links among two catechol rings in aqueous solutions has been identified during the catalytic oxidation with biomimetic iron-porphyrin by NMR spectroscopy. ${ }^{35}$ In agreement with previous studies, ${ }^{35}$ the coupling reaction is proposed to preferentially form $\mathrm{C}-\mathrm{C}$ bonds over the alternative aryloxy products with $\mathrm{C}-\mathrm{O}-\mathrm{C}$ groups.

Figure 5 shows the UV-visible spectrum of catechol, 1,2,3and 1,2,-4-trihydroxybenzene, which display $\pi \rightarrow \pi^{*}$ transitions at $\lambda=274.1,267.1$, and $290.2 \mathrm{~nm}$, respectively. However, these three polyphenols do not absorb visible light. Figure 5 also displays the spectrum of oxidized catechol.

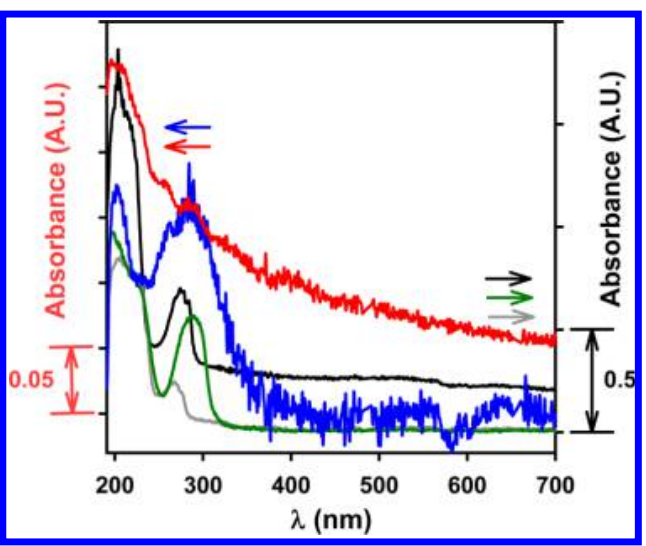

Figure 5. UV-visible absorption spectrum of thin films of (black) catechol, (gray) 1,2,3-trihydroxybenzene, (green) 1,2,4-trihydroxybenzene, (blue) cis,cis-muconic acid, and (red) oxidized catechol after $3 \mathrm{~h}$ under $23.6 \mathrm{ppmv}_{3}(\mathrm{~g})$ and $70 \% \mathrm{RH}$.

Figure 5 also shows that cis,cis-muconic acid alone cannot explain the various transitions recorded. The peaks at $\lambda=260$, 324 , and $407 \mathrm{~nm}$ in the UV-visible absorption spectrum for the oxidized film are due to the presence of cross-links from dimers and trimers of catechol and trihydroxybenzenes. ${ }^{36}$ 
Scheme 5. Proposed Reactions Producing Hexa- and Nona-hydroxy-biphenyls

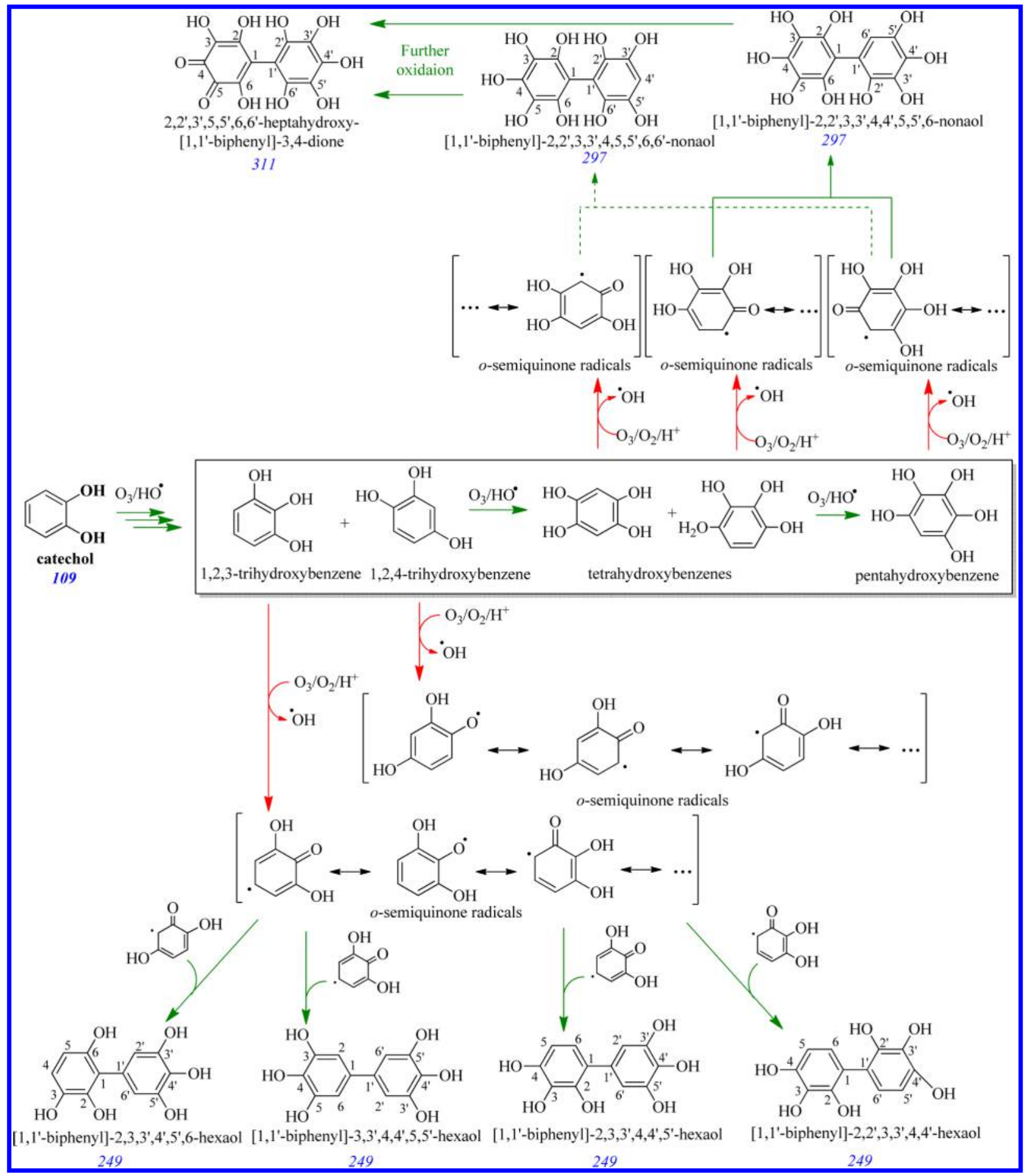

Similarly, the peak at $m / z 325$ in the ESI MS spectra of Figure 3 corresponds to a terphenyl arising from the combination of the semiquinone radicals of diphenyls and catechol (Scheme 4). Among the candidate products, three isomers displayed in Scheme 4 are $\left[1,1^{\prime}: 4^{\prime}, 1^{\prime \prime}\right.$-terphenyl $]-2^{\prime}, 3,3^{\prime}, 3^{\prime \prime}, 4,4^{\prime \prime}$-hexaol,

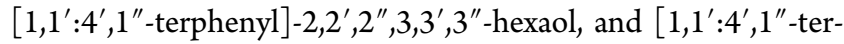

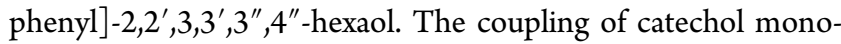
mer with formula mass $110 \mathrm{Da}$ to form dimers $(218 \mathrm{Da})$ and trimers $(326 \mathrm{Da})$ displays the expected characteristic pattern with a consecutive weight loss of $2 \mathrm{Da}$ per each new ringcarbon to ring-carbon bond. ${ }^{37}$
The species with $m / z 249$ in Figure 3 are assigned to a mixture of hexahydroxy-biphenyls such as [1,1'-biphenyl]$2,2^{\prime}, 3,3^{\prime}, 4,4^{\prime}$-hexaol, or any isomer such as those displayed in Scheme 5 to exemplify a few of them. Their production implies the combination of two semiquinone radicals from trihydroxybenzenes. Similarly, the production of tetra- and pentahydroxybenzenes precursors of their respective semiquinone radicals results in the generation of $\left[1,1^{\prime}\right.$-biphenyl]$2,2^{\prime}, 3,3^{\prime}, 4,5,5^{\prime}, 6,6^{\prime}$-nonaol or $\left[1,1^{\prime}\right.$-biphenyl $]$ $2,2^{\prime}, 3,3^{\prime}, 4,4^{\prime}, 5,5^{\prime}, 6$-nonaol, the candidate products in Scheme 5 with $m / z 297$. The production of $2,2^{\prime}, 3^{\prime}, 5,5^{\prime}, 6,6^{\prime}$-heptahydroxy-[1,1'-biphenyl]-3,4-dione with $m / z 311$ is presented in 
Scheme 5 as the result of further oxidation of both species with $m / z 297$. Finally, it is possible to compare the efficiency of the four different solvents during the extraction procedure of oxidized films based on their increasing polarities: chloroform $(1.04 \mathrm{D})<$ isopropanol $(1.56 \mathrm{D})<$ acetone $(2.88 \mathrm{D})<$ acetonitrile $(3.93 \mathrm{D}) .^{38}$ The hydroxyl group in isopropanol forms strong solvent-solute interactions to favorably dissolve the polyhydroxylated biphenyl and terphenyl products. In general, the higher-polarity solvents appear to be associated with an enhancement in the ion count of carboxylic acids in Figure 3.

The lack of any major peak pairs in the FTIR spectra of oxidized films (Figure 2) with comparable intensity in the $1050-1260 \mathrm{~cm}^{-1}$ interval for $\mathrm{C}-\mathrm{O}-\mathrm{C}$ stretches indicates that oxyphenylene products are not the dominant coupling products during the ozonolysis of catechol at the air-solid interface. ${ }^{39}$ More specifically, the absorbance for peaks located at $\sim 1120$ $\mathrm{cm}^{-1}$ (a broad feature) and $\sim 1220 \mathrm{~cm}^{-1}$, common features for two aromatic rings bound to a common oxygen atom, ${ }^{40}$ is very low, which demonstrates that if oxidiphenylenes are formed, they are much less abundant than biphenyl and triphenyl products. The previous analysis assumed that the combination of semiquinone radicals continuously produced during the reaction originates the products observed. However, a similar conclusion could be driven by considering the attack of the reactive radical species to abundant catechol molecules in the proximity of the solid film. Although Figures 3 and 4 display data for $71 \%$ relative humidity, the relative abundance of the various products is generally enhanced as $\mathrm{RH}$ rises. Further studies are underway to characterize this dependence.

Effect of RH on $\gamma_{\mathrm{O}_{3}}$. The loss of catechol and production of cis,cis-muconic acid during film oxidation under variable $\mathrm{RH}$ is displayed in Figure 6 for an $\mathrm{O}_{3}(\mathrm{~g})$ mixing ratio of $24.5 \mathrm{ppmv}$ between 0 and $90 \% \mathrm{RH}$. The presence of water alters the rate of reaction at the air-solid interface in agreement with related studies. $^{20}$ The normalized concentration of catechol to its initial value, $[$ catechol $] /[\text { catechol }]_{0}$, is obtained from the change of the $\mathrm{CD}$ line relative to its initial value $\mathrm{CD}_{0}$ line in panel $\mathrm{A}$ of Figure 6. For this purpose, the loss of $\mathrm{C}(\mathrm{Ar})=\mathrm{C}(\mathrm{Ar})$ stretching

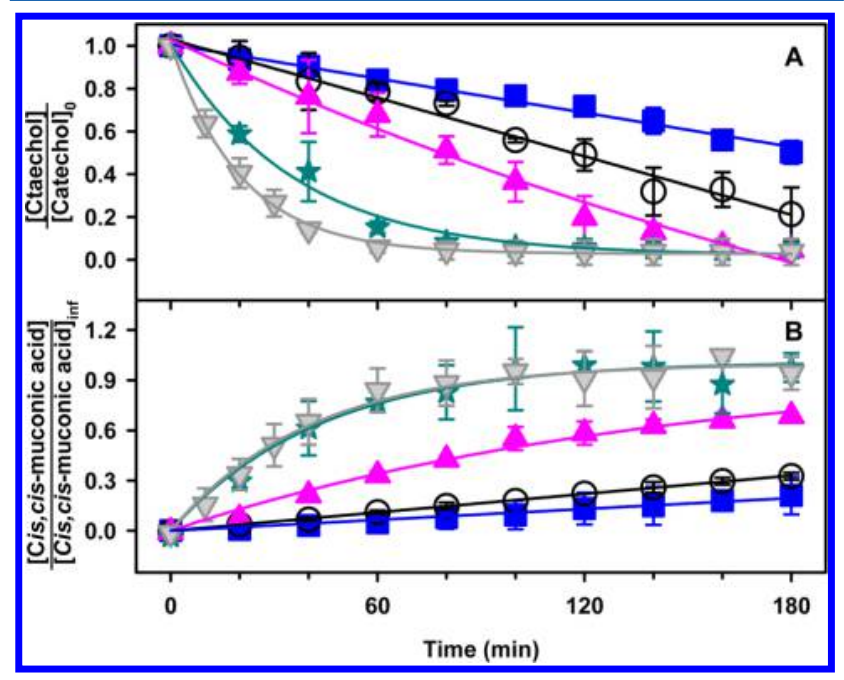

Figure 6. (A) Normalized loss of catechol (peak 2 in Figure 2) and (B) relative production of cis,cis-muconic acid (peak 4 in Figure 2) over $3 \mathrm{~h}$ of exposure to $24.5 \mathrm{ppmv} \mathrm{O}_{3}(\mathrm{~g})$ at (blue squares) $0 \%$, (black open circles) $29 \%$, (pink triangles) $48 \%$, (teal stars) $72 \%$, and (gray triangles) $90 \% \mathrm{RH}$. of catechol at $1363 \mathrm{~cm}^{-1}$ is used to fit a three-parameter exponential decay equation $[$ catechol $]=[\text { catechol }]_{0}+$ $a \exp \left(-k_{\text {catechol }+\mathrm{O}_{3}} t\right)$, where $a$ is the pre-exponential constant and $k_{\text {catechol }+\mathrm{O}_{3}}$ is the reaction rate constant.

Figure 3B shows the relative growth of [cis,cis-muconic acid] at time $t$ relative to its final concentration [cis,cis-muconic acid $]_{\text {inf }}$ obtained from an extrapolation of the $\mathrm{C}=\mathrm{O}$ stretching at $1680 \mathrm{~cm}^{-1}$ as $t \rightarrow \infty, C_{\text {inf }}$ line. The fitted curves in Figure $6 \mathrm{~B}$ correspond to two-parameter exponential growth curves of the form [cis,cis-muconic acid $] /[\text { cis,cis-muconic acid }]_{\text {inf }}=1-$ $\exp \left(-k_{c i s, c i s-m u c o n i c ~ a c i d} t\right)$, where the pseudo-first-order rate

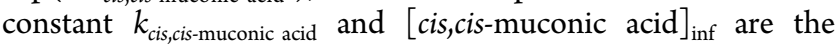
fitted parameters. Both pseudo-first-order rate constants, $k_{\text {catechol }+\mathrm{O}_{3}}$ and $k_{\text {cis,cis-muconic acid }}$ at variable $\mathrm{RH}$ are available in Table S9 (Supporting Information).

The data in Figure 6 for $\left[\mathrm{O}_{3}(\mathrm{~g})\right]=6 \times 10^{14}$ molecules $\mathrm{cm}^{-3}$ is within the low-concentration range that shows a linear dependence of the rate constant with $\left[\mathrm{O}_{3}(\mathrm{~g})\right]$ in the Langmuir-Hinshelwood mechanism. ${ }^{25}$ Therefore, in the presence of water, the ozonolysis of catechol at the air-solid interface (Figure 6) follows a first-order kinetics in both ozone and catechol concentrations. ${ }^{41}$ A possible explanation for the enhanced reaction rates observed in Figure $3 \mathrm{~A}$ for higher $\mathrm{RH}$ is related to the orientation of catechol's $\mathrm{O}-\mathrm{H}$ groups toward the interface. These $\mathrm{O}-\mathrm{H}$ groups provide sites for water adsorption to the film that facilitate the attack to the vicinal $\mathrm{C}_{1}-\mathrm{C}_{2}$ bond resulting in the production of cis,cis-muconic acid (Scheme 2). Similarly, the reaction forming the $\mathrm{C}=\mathrm{O}$ groups of cis,cismuconic acid becomes more important with increasing $\mathrm{RH}$ (Figure 6B). For the two highest $\mathrm{RH}$ tested of 71 and $90 \%$, the production of cis,cis-muconic acid levels off after $1.5 \mathrm{~h}$, conditions under which other carboxylic acids such as glyoxylic and maleic acids are observed by ESI MS analysis. Overall, these results imply that water facilitates the formation of carboxylic acids during the heterogeneous oxidation of catechol. Once formed, carboxylic acids can act as a source of protons for acid catalysis, which reaches a converging maximum above a threshold of $\sim 70 \% \mathrm{RH}$.

The reactive uptake coefficient of $\mathrm{O}_{3}(\mathrm{~g})$ by catechol, $\gamma_{\mathrm{O}_{3}}$, is calculated based on eq $1^{42}$

$$
\gamma_{\mathrm{O}_{3}}=\frac{4 R T}{\nu_{\mathrm{O}_{3}}} \delta \frac{k_{\text {catechol }+\mathrm{O}_{3}}}{P_{\mathrm{O}_{3}}}[\text { catechol }]
$$

and plotted in Figure 7. This equation accounts for the fraction of reactive collisions relative to the total rate of collisions obtained from kinetic theory of gases. In eq $1, R=8.314 \mathrm{~J}$ $\mathrm{K}^{-1} \mathrm{~mol}^{-1}$ is the gas constant, and $\nu_{\mathrm{O}_{3}}=394 \mathrm{~m} \mathrm{~s}^{-1}$ is the mean thermal velocity of $\mathrm{O}_{3}(\mathrm{~g})$ at $T=298 \mathrm{~K} . k_{\text {catechol }+\mathrm{O}_{3}}\left(\mathrm{~s}^{-1}\right)$ are the measured values (Table S9). The partial pressure of ozone $P_{\mathrm{O}_{3}}$ $(\mathrm{Pa})$ is known from UV absorption spectroscopy, and the effective film thickness $\delta=8.4 \times 10^{-8} \mathrm{~m}$ is estimated for a uniform surface coverage of catechol $\left(8.20 \times 10^{17}\right.$ molecules $)$ deposited over the IR-transparent crystal of area $S_{\mathrm{A}}=1.32 \times$ $10^{-4} \mathrm{~m}^{2}$; and [catechol] $=1.217 \times 10^{4}$ molecules $\mathrm{m}^{-3}$ based on catechol density of $1340 \mathrm{~kg} \mathrm{~m}^{-3}$ and formula mass of $110.1 \times$ $10^{-3} \mathrm{~kg} \mathrm{~mol}^{-1}$.

The large flow of $\mathrm{O}_{3}(\mathrm{~g})$ into the reactor favors a turbulent flow, which together with the very small reaction probabilities measured $\left(<10^{-5}\right)$ indicate that the diffusion of $\mathrm{O}_{3}(\mathrm{~g})$ to the surface is not a limiting factor in our reactor. For comparison, 


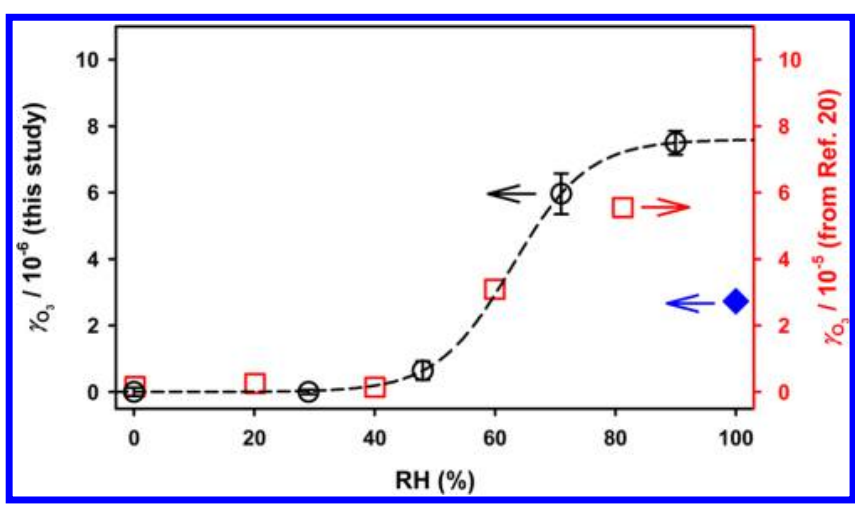

Figure 7. Reactive uptake coefficient of $\mathrm{O}_{3}(\mathrm{~g})$ by catechol thin film at variable RH. Measured (black circles) in this study for $24.5 \mathrm{ppmv}$ $\mathrm{O}_{3}(\mathrm{~g})$ and (red squares), in ref 20, for 4 ppmv $\mathrm{O}_{3}(\mathrm{~g})$, and (solid blue diamond) at the air-water interface in ref 17 .

Figure 7 also includes reactive uptake coefficients estimated at the air-water interface ${ }^{17}$ (expressed as $\mathrm{RH}=100 \%$ ) and reported in the literature ${ }^{20}$ under similar conditions. Remarkably, the trends of both studies in Figure 7 (black circles and red squares) closely match each other; however, their vertical scale is shifted an order of magnitude, clearly reflecting a difference in the calculation of $\gamma_{\mathrm{O}_{3}}$. For example, at $90 \% \mathrm{RH}$, the maximum $\gamma_{\mathrm{O}_{3}}=(7.49 \pm 0.35) \times 10^{-6}$ measured for $24.5 \mathrm{ppmv}$ $\mathrm{O}_{3}(\mathrm{~g})$ in this study is 7.5-times smaller than the value from ref $20\left(5.6 \times 10^{-5}\right.$ for $4 \mathrm{ppm} \mathrm{O}_{3}(\mathrm{~g})$ at $\left.\mathrm{RH}=81 \%\right)$ but only 2.7 times larger than the one estimated at the air-water interface. ${ }^{17}$ In principle, this comparison suggests a smaller upper limit for the uptake coefficient of ozone by catechol to be used for modeling the behavior of the emissions from combustion and biomass burning under humid conditions. However, considering that $\gamma_{\mathrm{O}_{3}}$ should vary with $\left[\mathrm{O}_{3}(\mathrm{~g})\right]$ following a LangmuirHinshelwood dependence from $k_{\text {catechol }+\mathrm{O}_{3}}$, the reported discrepancy for $\gamma_{\mathrm{O}_{3}}$ could simply reflect the $\sim 6$-times ratio in concentrations used in both studies. To gain further insight about this system, future experimental work should aim to determine the Langmuir-Hinshelwood dependence of the reaction rate constant on $\left[\mathrm{O}_{3}(\mathrm{~g})\right]$

\section{ATMOSPHERIC IMPLICATIONS AND CONCLUSIONS}

This work shows how catechol, a model compound emitted during biomass burning and combustion emissions, is used to study the heterogeneous processing of the oxygenated fraction of aromatic hydrocarbons under variable $\mathrm{RH}$. Similar chemical processing is expected for other aromatic surfaces in contact with the atmosphere (e.g., urban films, aerosols, etc.). After primary oxidation of aromatic surfaces by $\mathrm{HO}^{\circ}$, the sequential production of 1-hydroxy- and 1,2-dihydroxy-substituted aromatics should continue in a fashion similar to the one described in this work.

In our experimental system, ozone-driven oxidation of catechol in the presence of water vapor leads to the generation of $o$-semiquinone radicals and secondary oxidants, including $\mathrm{HO}^{\bullet}, \mathrm{HO}_{2}^{\bullet}$, and $\mathrm{H}_{2} \mathrm{O}_{2}$, which further promote the aging of organic material. Similar processes could occur in atmospheric aerosols generated by combustion and biomass burning. The products identified in this study demonstrate that heterogeneous reactions can provide oxidants and radicals to the atmosphere. ${ }^{17}$ The competitive production of polyhydroxylated biphenyls and terphenyls proceeds at the air-solid interface together with the cleavage of the $\mathrm{C}_{1}-\mathrm{C}_{2}$ bond of catechol by ozonolysis. The absorptivity of model oxidized organic material representing these emissions becomes pronounced at $\lambda>290$ $\mathrm{nm}$. In addition, the gradual increase in absorptivity with decreasing wavelength, when transitioning from the visible to the UV, directly resembles the behavior of atmospheric brown carbon. ${ }^{43-46}$ The prompt oxidation of aromatic species by abundant $\mathrm{HO}^{\bullet}$ generates polyphenols that are prone to undergo direct ozonolysis to form carboxylic acids as a competitive aging mechanism at the air-solid interface in the presence of water molecules. The products detected in this study are consistent with the charge-transfer complexes recently reported in water-extracted ambient particulate matter collected in Athens, Georgia. ${ }^{47}$ Even in dry desert environments (e.g., Mojave and Great Basin Desert), where the range of $\mathrm{RH}$ is between $\sim 15 \%$ and $\sim 72 \%$ (comparable to the global-mean $\mathrm{RH}$ $=77 \%),{ }^{48} \gamma_{\mathrm{O}_{3}}$ will depend strongly on humidity as described above.

For particles of surface $A$ with a mean diameter of $100 \mathrm{~nm}$ covered by catechol molecules, the reaction rate with $\left[\mathrm{O}_{3}(\mathrm{~g})\right]=$ $2.46 \times 10^{12}$ molecules $\mathrm{cm}^{-3}$ relative to that with $[\mathrm{OH}(\mathrm{g})]=1.6$ $\times 10^{6}$ molecules $\mathrm{cm}^{-3}$ is $^{49}\left(\gamma_{\mathrm{O}_{3}}\left[\mathrm{O}_{3}(\mathrm{~g})\right] v_{\mathrm{O}_{3}} A / 4\right) /\left(\gamma_{\mathrm{OH}}[\mathrm{OH}(\mathrm{g})]\right.$ $\left.v_{\mathrm{OH}} A / 4\right)=6.9$, where room temperature is assumed; $\gamma_{\mathrm{O}_{3}}=7.49$ $\times 10^{-6}$ for $\mathrm{RH}=90 \%, \gamma_{\mathrm{OH}}=1$ is employed as an upper limit, and the mean thermal velocity of $\mathrm{OH}$ radicals is $v_{\mathrm{OH}}=661$ $\mathrm{m} \mathrm{s}^{-1}$. Therefore, ozonolysis may be at least 7-times faster than the loss of catechol by $\mathrm{HO}^{-}$during interfacial reactions. Moreover, the heterogeneous processing of hydroxylated aromatics by this mechanism is expected to become important in the absence of $\mathrm{HO}^{\bullet}$ during nighttime.

Overall, pollution plumes with tropospheric residence time of $\sim 1$ week against deposition ${ }^{50}$ contribute to the oxidative aging of aromatics during transport. These aging mechanisms produce low-volatility species ${ }^{51}$ such as oxalic acid and low molecular weight oxocarboxylic and unsaturated dicarboxylic acids found in SOA. ${ }^{9,11}$ Monitoring reactions occurring at surfaces contributes to enhancing our understanding of key heterogeneous processes, ${ }^{52,53}$ while contributing reaction mechanisms to explain atmospheric observations. Heterogeneous reactions provide a connection between the processing of combustion and biomass burning emissions and the ubiquitous generation of brown carbon species ${ }^{54}$ resulting from pathways not yet considered in atmospheric models.

\section{ASSOCIATED CONTENT}

\section{S Supporting Information}

The Supporting Information is available free of charge on the ACS Publications website at DOI: 10.1021/acs.jpca.5b07914.

$$
\text { Additional Tables S1-S9 (PDF) }
$$

\section{AUTHOR INFORMATION}

\section{Corresponding Author}

*E-mail: marcelo.guzman@uky.edu. Phone: (859)323-2892.

\section{Notes}

The authors declare no competing financial interest.

\section{ACKNOWLEDGMENTS}

We thank research funding from NSF CAREER award (CHE1255290). 


\section{REFERENCES}

(1) Boucher, O.; Randall, D.; Artaxo, P.; Bretherton, C.; Feingold, G.; Forster, P.; Kerminen, V.-M.; Kondo, Y.; Liao, H.; Lohmann, U. et al. Clouds and Aerosols. In Climate change 2013: The physical science basis. Contribution of working group I to the fifth assessment report of the intergovernmental panel on climate change; Stocker, T. F., Qin, D., Plattner, G.-K., Tignor, M., Allen, S. K., Boschung, J., Nauels, A., Xia, Y., Bex, V., Midgley, P. M., Eds.; Cambridge University Press: Cambridge, United Kingdom and New York, 2013.

(2) Hallquist, M.; Wenger, J. C.; Baltensperger, U.; Rudich, Y.; Simpson, D.; Claeys, M.; Dommen, J.; Donahue, N. M.; George, C.; Goldstein, A. H.; et al. The formation, properties and impact of secondary organic aerosol: current and emerging issues. Atmos. Chem. Phvs. 2009, 9, 5155-5236.

(3) Finlayson-Pitts, B. J. Reactions at surfaces in the atmosphere: integration of experiments and theory as necessary (but not necessarily sufficient) for predicting the physical chemistry of aerosols. Phvs. Chem. Chem. Phvs. 2009, 11, 7760-7779.

(4) Rudich, Y.; Donahue, N. M.; Mentel, T. F. Aging of organic aerosol: Bridging the gap between laboratory and field studies. Annu. Rev. Phvs. Chem. 2007, 58, 321-352.

(5) Mkoma, S. L.; Kawamura, K. Molecular composition of dicarboxylic acids, ketocarboxylic acids, $\alpha$-dicarbonyls and fatty acids in atmospheric aerosols from Tanzania, East Africa during wet and dry seasons. Atmos. Chem. Phvs. 2013, 13, 2235-2251.

(6) Kawamura, K.; Tachibana, E.; Okuzawa, K.; Aggarwal, S. G.; Kanaya, Y.; Wang, Z. F. High abundances of water-soluble dicarboxylic acids, ketocarboxylic acids and $\alpha$-dicarbonyls in the mountaintop aerosols over the North China Plain during wheat burning season. Atmos. Chem. Phvs. 2013, 13, 8285-8302.

(7) Kundu, S.; Kawamura, K.; Andreae, T. W.; Hoffer, A.; Andreae, M. O. Molecular distributions of dicarboxylic acids, ketocarboxylic acids and $\alpha$-dicarbonyls in biomass burning aerosols: Implications for photochemical production and degradation in smoke layers. Atmos. Chem. Phvs. 2010, 10, 2209-2225.

(8) Yang, L.; Nguyen, D. M.; Jia, S.; Reid, J. S.; Yu, L. E. Impacts of biomass burning smoke on the distributions and concentrations of $\mathrm{C}_{2}-\mathrm{C}_{5}$ dicarboxylic acids and dicarboxylates in a tropical urban environment. Atmos. Environ. 2013, 78, 211-218.

(9) Veres, P.; Roberts, J. M.; Burling, I. R.; Warneke, C.; de Gouw, J.; Yokelson, R. J. Measurements of gas-phase inorganic and organic acids from biomass fires by negative-ion proton-transfer chemical-ionization mass spectrometry. I. Geophvs. Res. 2010, 115, D23302.

(10) Adounkpe, J.; Aina, M.; Mama, D.; Sinsin, B. Gas chromatography mass spectrometry identification of labile radicals formed during pyrolysis of catechol, hydroquinone, and phenol through neutral pyrolysis product mass analysis. ISRN Environ. Chem. 2013, 2013, 1.

(11) Desyaterik, Y.; Sun, Y.; Shen, X.; Lee, T.; Wang, X.; Wang, T.; Collett, J. L. Speciation of "brown" carbon in cloud water impacted by agricultural biomass burning in eastern China. I. Geophys. Res.-Atmos. 2013, 118, 7389-7399.

(12) Dharaiya, N.; Bahadur, P. Phenol induced growth in Triton X100 micelles: Effect of $\mathrm{pH}$ and phenols' hydrophobicity. Colloids Surf. A 2012, 410, 81-90.

(13) Latif, M. T.; Brimblecombe, P. Surfactants in atmospheric aerosols. Environ. Sci. Technol. 2004, 38, 6501-6506.

(14) Zein, A. E.; Coeur, C.; Obeid, E.; Lauraguais, A.; Fagniez, T. Reaction kinetics of catechol (1,2-benzenediol) and guaiacol (2methoxyphenol) with ozone. I. Phvs. Chem. A 2015, 119, 6759-6765.

(15) Guzman, M. I.; Athalye, R. R.; Rodriguez, J. M. Concentration effects and ion properties controlling the fractionation of halides during aerosol formation. I. Phvs. Chem. A 2012, 116, 5428-5435.

(16) Pillar, E. A.; Guzman, M. I.; Rodriguez, J. M. Conversion of iodide to hypoiodous acid and iodine in aqueous microdroplets exposed to ozone. Environ. Sci. Technol. 2013, 47, 10971-10979.

(17) Pillar, E. A.; Camm, R. C.; Guzman, M. I. Catechol oxidation by ozone and hydroxyl radicals at the air-water interface. Environ. Sci. Technol. 2014, 48, 14352-14360.
(18) Guzman, M. I.; Pillar, E. A. Ozonation of aromatic hydrocarbon probes at the air-water interface. In 248th ACS National Meeting \& Exposition, San Francisco, CA, August 10-14, 2014; American Chemical Society: Washington, DC, 2014; pp COLL-93.

(19) Woodill, L. A.; O’Neill, E. M.; Hinrichs, R. Z. Impacts of surface adsorbed catechol on tropospheric aerosol surrogates: Heterogeneous ozonolysis and its effects on water uptake. I. Phys. Chem. A 2013, 117, $5620-5631$

(20) Barnum, T. J.; Medeiros, N.; Hinrichs, R. Z. Condensed-phase versus gas-phase ozonolysis of catechol: A combined experimental and ttheoretical study. Atmos. Environ. 2012, 55, 98-106.

(21) Ofner, J.; Krüger, H. U.; Zetzsch, C. Time resolved infrared spectroscopy of formation and processing of secondary organic aerosol. Z. Phvs. Chem. 2010, 224, 1171-1183.

(22) Sander, S. P.; Abbatt, J.; Barker, J. R.; Burkholder, J. B.; Friedl, R. R.; Golden, D. M.; Huie, R. E.; Kolb, C. E.; Kurylo, M. J.; Moortgat, G. $\mathrm{K}$. et al. Chemical kinetics and photochemical data for use in atmospheric studies: Evaluation number 17; Jet Propulsion Laboratory, California Institute of Technology, Pasadena, CA, http:// jpldataeval.jpl.nasa.gov, 2011 (accessed June 7, 2015).

(23) Zhou, R.; Guzman, M. I. $\mathrm{CO}_{2}$ reduction under periodic illumination of ZnS. I. Phys. Chem. C 2014, 118, 11649-11656.

(24) Han, S.-q.; Zhang, M.; Zhao, C.-s.; Lu, X.-q.; Ran, L.; Han, M.; Li, P.-y.; Li, X.-j. Differences in ozone photochemical characteristics between the megacity Tianjin and its rural surroundings. Atmos. Environ. 2013, 79, 209-216.

(25) Pillar, E. A.; Guzman, M. I. Ozonolysis of catechol at the gassolid interface. 250th ACS National Meeting \& Exposition, 2015, Boston, MA, August 16-20, 2015; pp PHYS-295.

(26) Sǒhár, P.; Varsányi, G. Y. An IR spectroscopic study of muconate isomers. I. Mol. Struct. 1968, 1, 437-448.

(27) Mvula, E.; von Sonntag, C. Ozonolysis of phenols in aqueous solution. Org. Biomol. Chem. 2003, 1, 1749-1756.

(28) Bailey, P. S. Ozonation in Organic Chemistrvi Academic Press: New York, 1982; Vol. 2.

(29) Ramseier, M. K.; von Gunten, U. Mechanisms of phenol ozonation-kinetics of formation of primary and secondary reaction products. Ozone: Sci. Eng. 2009, 31, 201-215.

(30) ten Brink, G. J.; Arends, I. W. C. E.; Sheldon, R. A. The BaeyerVilliger reaction: New developments toward greener procedures. Chem. Rev. 2004, 104, 4105-4124.

(31) Flyunt, R.; Leitzke, A.; Mark, G.; Mvula, E.; Reisz, E.; Schick, R.; von Sonntag, C. Determination of ${ }^{\bullet} \mathrm{OH}, \mathrm{O}_{2}{ }^{\bullet}$, and hydroperoxide yields in ozone reactions in aqueous solution. I. Phys. Chem. B 2003, $107,7242-7253$

(32) Buxton, G. V.; Greenstock, C. L.; Helman, W. P.; Ross, A. B. Critical review of rate constants for reactions of hydrated electrons, hydrogen atoms and hydroxyl radicals $\left({ }^{\circ} \mathrm{OH} /{ }^{\circ} \mathrm{O}^{-}\right)$in aqueous solution. I. Phys. Chem. Ref. Data 1988, 17, 513-886.

(33) Von Sonntag, C.; Von Gunten, U. Chemistry of Ozone in Water and Wastewater Treatment: From Basic Principles to Applications; IWA Publishing: London, 2012.

(34) Iwaki, R.; Kamiya, I. Chemiluminescent reaction between polyphenols and ozone in acetic acid. Bull. Chem. Soc. Ipn. 1969, 42, $855-863$.

(35) Šmejkalová, D.; Conte, P.; Piccolo, A. Structural characterization of isomeric dimers from the oxidative oligomerization of catechol with a biomimetic catalyst. Biomacromolecules 2007, 8, 737-743.

(36) Kandaswami, C.; Subba Rao, P. V.; Nair, P. M.; Vaidyanathan, C. S. Oxidation of catechol in higher plants. I. Enzymic conversion of catechol to 3,4,3',4'-tetrahydroxydiphenyl. Can. I. Biochem. 1969, 47, 375-377.

(37) Yang, J.; Cohen Stuart, M. A.; Kamperman, M. Jack of all trades: versatile catechol crosslinking mechanisms. Chem. Soc. Rev. 2014, 43, 8271-8298.

(38) CRC Handbook of Chemistry and Physics, 93rd ed.; CRC Press/ Taylor and Francis: Boca Raton, FL, 2013. 
(39) Sun, X.; Bai, R.; Zhang, Y.; Wang, Q.; Fan, X.; Yuan, J.; Cui, L.; Wang, P. Laccase-catalyzed oxidative polymerization of phenolic compounds. Appl. Biochem. Biotechnol. 2013, 171, 1673-1680.

(40) Mita, N.; Tawaki, S.-i.; Uyama, H.; Kobayashi, S. Laccasecatalyzed oxidative polymerization of phenols. Macromol. Biosci. 2003, 3, 253-257.

(41) Gurol, M. D.; Nekouinaini, S. Kinetic behavior of ozone in aqueous solutions of substituted phenols. Ind. Eng. Chem. Fundam. 1984, 23, 54-60.

(42) Hung, H.-M.; Ariya, P. Oxidation of oleic acid and oleic acid/ sodium chloride(aq) mixture droplets with ozone: Changes of hygroscopicity and role of secondary reactions. I. Phys. Chem. A 2007, 111, 620-632.

(43) Rincón, A. G.; Guzmán, M. I.; Hoffmann, M. R.; Colussi, A. J. Optical absorptivity versus molecular composition of model organic aerosol matter. I. Phys. Chem. A 2009, 113, 10512-10520.

(44) Rincón, A. G.; Guzmán, M. I.; Hoffmann, M. R.; Colussi, A. J. Thermochromism of model organic aerosol matter. I. Phvs. Chem. Lett. 2010, 1, 368-373.

(45) Saleh, R.; Robinson, E. S.; Tkacik, D. S.; Ahern, A. T.; Liu, S.; Aiken, A. C.; Sullivan, R. C.; Presto, A. A.; Dubey, M. K.; Yokelson, R. $\mathrm{J}$;; et al. Brownness of organics in aerosols from biomass burning linked to their black carbon content. Nat. Geosci. 2014, 7, 647-650.

(46) Hecobian, A.; Zhang, X.; Zheng, M.; Frank, N.; Edgerton, E. S.; Weber, R. J. Water-soluble organic aerosol material and the lightabsorption characteristics of aqueous extracts measured over the southeastern united states. Atmos. Chem. Phvs. 2010, 10, 5965-5977.

(47) Phillips, S. M.; Smith, G. D. Light absorption by charge transfer complexes in brown carbon aerosols. Environ. Sci. Technol. Lett. 2014, $1,382-386$

(48) Hartmann, D. L. Global Physical Climatology; Academic Press: San Diego, CA, 1994.

(49) George, I. J.; Abbatt, J. P. D. Heterogeneous Oxidation of Atmospheric Aerosol Particles by Gas-phase Radicals. Nat. Chem. 2010, 2, 713-722.

(50) Seinfeld, J. H.; Pandis, S. N. Atmospheric Chemistry and Physics: From Air Pollution to Climate Change, 2nd ed.; Wiley: New York, 2006.

(51) Saleh, R.; Hennigan, C. J.; McMeeking, G. R.; Chuang, W. K.; Robinson, E. S.; Coe, H.; Donahue, N. M.; Robinson, A. L. Absorptivity of brown carbon in fresh and photo-chemically aged biomass-burning emissions. Atmos. Chem. Phvs. 2013, 13, 7683-7693.

(52) Dubowski, Y.; Vieceli, J.; Tobias, D. J.; Gomez, A.; Lin, A.; Nizkorodov, S. A.; McIntire, T. M.; Finlayson-Pitts, B. J. Interaction of gas-phase ozone at $296 \mathrm{~K}$ with unsaturated self-assembled monolayers: A new look at an old system. L. Phys. Chem. A 2004, 108, 1047310485.

(53) George, C.; Ammann, M.; D’Anna, B.; Donaldson, D. J.; Nizkorodov, S. A. Heterogeneous photochemistry in the atmosphere. Chem. Rev. 2015, 115, 4218-4258.

(54) Laskin, A.; Laskin, J.; Nizkorodov, S. A. Chemistry of atmospheric brown carbon. Chem. Rev. 2015, 115, 4335-4382. 